\title{
Study on the Shear Behavior of RC deep beam strengthening by FRP HuaXin LIU ${ }^{a}$, XiaoKun WANG, XueZhi WANG \\ Civil Engineering \& Architecture College, Liaoning University of Technology, Jinzhou, China aroro97@126.com, ${ }^{a}$ Igliuhuaxin@163.com
}

Keywords: deep beam; FRP; Reinforcement for shearing; STM.

\begin{abstract}
The development of tall building requires better design of deep beam. Blindly increasing the section size and the amount of bar are not the best way. Along with the development of the reinforcement of FRP, combining the reinforcement of FRP with the deep beam is perhaps a good method. The main standpoints of this task are: Reinforcement of FRP, CFRP and GFRP are more than BFRP, but the price of CFRP is much higher, the endurance of GFRP is bad at alkaline environment, and the comprehensive performance of BFRP is well; Reinforcement of FRP in beams, Reinforcement for shearing are more than reinforcement for bending, Shallow beam are more than deep beam. Reinforcement for shearing of deep beam are much less; The theory of deep beam's calculation, STM method must replace the traditional method which bases on half-experience and half-theory; Reinforcement for shearing of deep beam using FRP should include examination, theoretic analysis and simulation analysis 3 aspects.
\end{abstract}

\section{Introduction}

Strengthening beams are common in renovation projects. Different people have different ways to reinforce the basic beam consisted of concrete and bars. For example, increasing section size, using fiber concrete instead of normal concrete, coating beams with steels or FRP cloth, excavating troughs near the surface of beams and then put FRP boards or FRP bars into the troughs(near surface method, NSM for short).Every method has it's own advantages and disadvantages, but NSM must be the tendency in the coning years. This is also our reinforcement method of deep beam $^{[1]}$.

\section{Reinforcement material}

In NSM, there are 4 types of FRP which we use them widely now: AFRP、BFRP、CFRP and GFRP.

Researchment of BFRP is much few than other FRP. Our country had issued 《Technical Specification for Strengthening Concrete Structure with Carbon Fiber Reinforced Polymer》 (CECS146:2003), but then《Design code for strengthening concrete structure》(GB50367-2006) took place of it, the latest national standard is 《Carbon fiber sheet for strengthening and restoring structures》(GB/T21490-2008). It is clear that CFRP is mature, but the price of CFRP is high.

We use BFRP bar with surface sand-blasting ${ }^{[3 \sim 4]}$, not BFRP board.

\section{Reinforcement method}

Correlative research about NSM have just raised from 5 or 6 years ago. When we excavate troughs near the bottom surface of beam, it is the reinforcement for bending, when near the side surface, it is the reinforcement for shearing. Research on later are much less than former. But both of them are equal important to safety of structure, so we need to do more things about reinforcement for shearing of beam.

A similar state of affairs exists between the shallow beam and deep beam. At this point, we will try to band reinforcement for shearing together deep beam, in other words, we will try to research reinforcement for shearing of deep beam. Referential experience is few. we have to keep questing 
and trying $^{[5]}$.

\section{Theory of deep beam}

Theory of deep beam is a complicated problem, although our country has our own code ${ }^{[6]}$ to design deep beam, but part of formulas comes from foreign, like USA. Strut-and-tie model(STM for short) in ACI is a reasonable method to solve deep beam's design problem.

Cultural difference between east and west makes great gap in the field of dynamics. But industrious Chinese people never give up to pursue scientific knowledge, researcher like Ye Lie-ping and Gong Jin-xin are bending themselves to look for methods which fit for China's actual conditions $^{[7 \sim 8]}$.

\section{Research about reinforcement for shearing of deep beam}

Design of experimental deep beam. We complied our calculated sheet on the basis of 《Code for design of concrete structures》 (GB50010-2010) ${ }^{[7]}$,the rebar skeleton is as Fig 1:

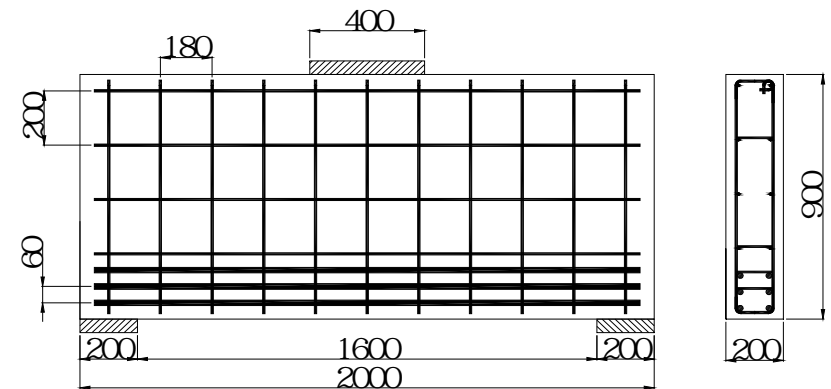

Fig.1. the rebar skeleton

The deep beam's steel skeleton includes 6 longitudinal reinforcements 、 8 horizontal distribution steels 22 vertical distribution steels 20 tie bars. In addition, there are 2 kinds of steel backing plates at bearing chairs and mid-span to prevent local destroy.

There are 6 longitudinal reinforcements at the bottom of deep beam, which anchor by steel plate with pores, like Fig 2 and 3.
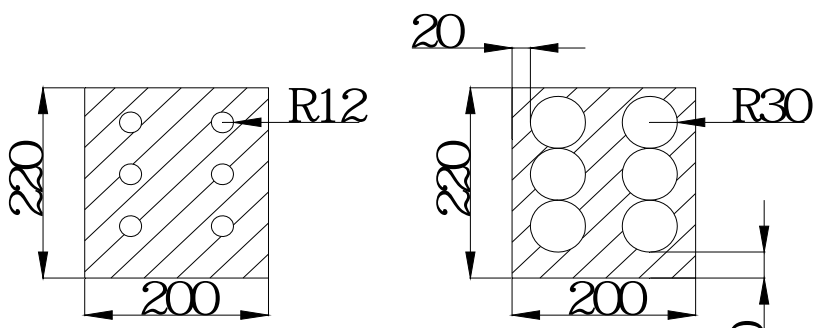

\&

Fig.2. steel plate with pores

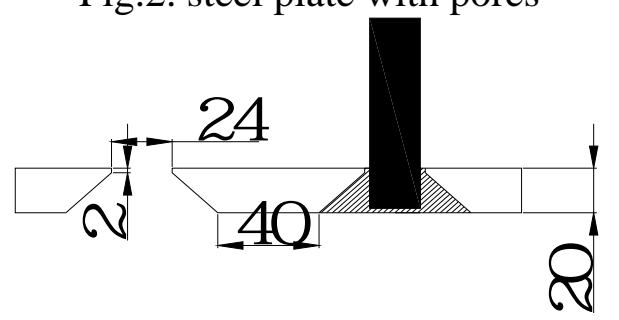

Fig.3.welding connection

Reinforcement method. Referential experience about reinforcement for shearing of deep beam is few. An embryonic idea is as follows Fig 4 and 5: 

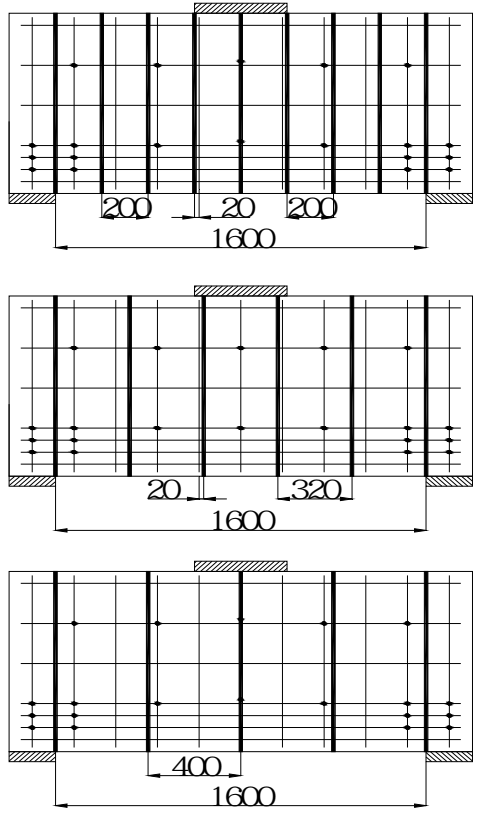

Fig.4.reinforcement of elevation
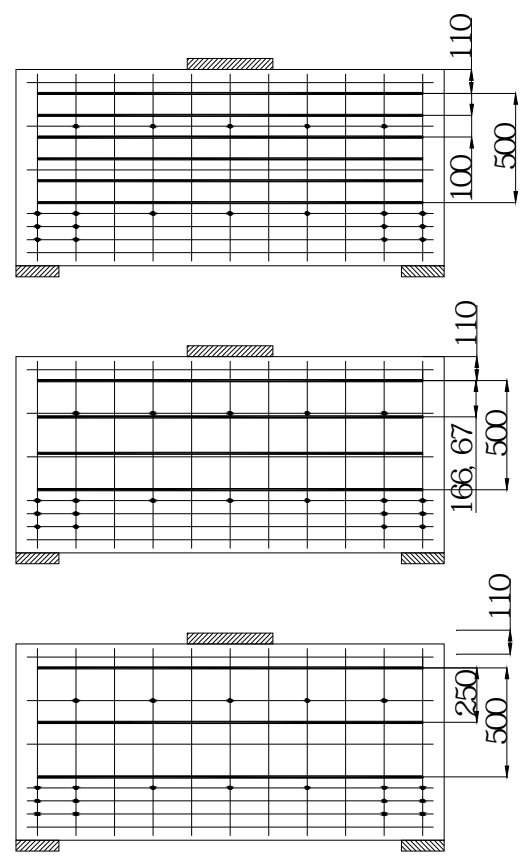

Fig.5. reinforcement of horizontal

There are 3 groups, first is a deep beam unreinforced like Fig 1.Second is like Fig 4.Third is like Fig 5, so there are 7 deep beams,2 reinforcement methods totally. We only consider different space of BFRP bars like Fig 4 and 5.

NSM detailed drawing. The trough is $15 \mathrm{~mm} * 18 \mathrm{~mm}, \mathrm{BFRP}$ bar is $10 \mathrm{~mm}^{[2]}$,the detailed drawing is like Fig 6.

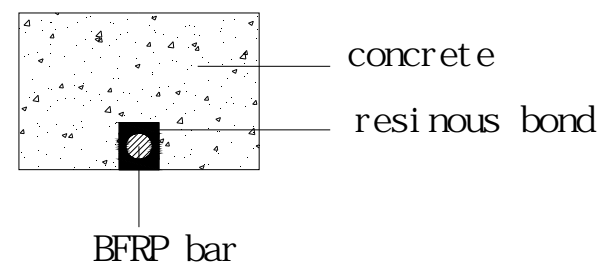

Fig.6.NSM of BFRP bar

Design foundation. We need our beams to occur shear failure, not bending failure. So when we design the deep beam unreinforced, the shear-bearing capacity and bending capacity is like Fig 7:

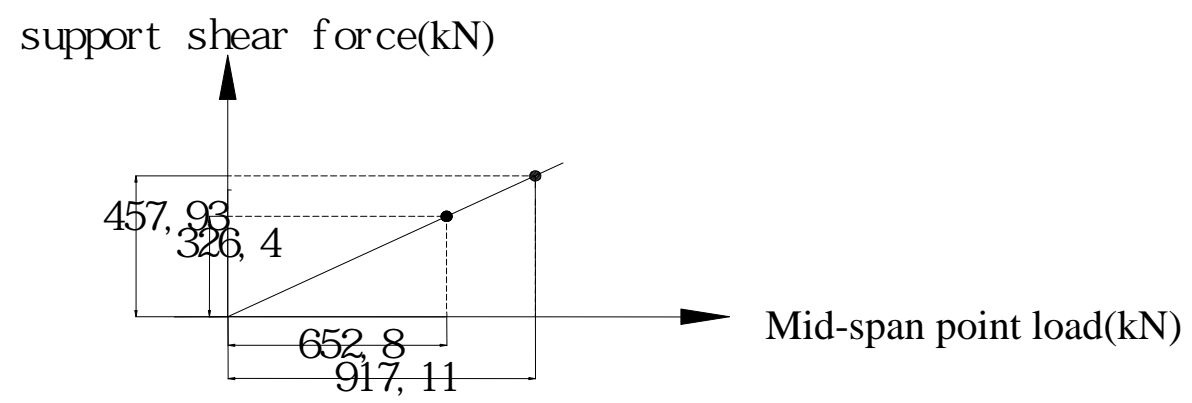

Fig.7.shearing and bending capacity of deep beam unreinforced

The mid-span load is a uniformly distributed load because of the exist of the steel backing plate, but it can equivalent to a point load like Fig 7's horizontal axis. The vertical axis is support shear force. Their proportion is $2: 1$.

When the mid-span point load increase to $652.8 \mathrm{kN}$,deep beam occur shear failure, when $917.11 \mathrm{kN}$,bending failure, the deep beam unreinforced, group 1 too, must occur shear failure, if the reinforcement for shearing increase extent don't surpass $40 \%(917.11 / 652.8=1.4)$, the beams reinforced, group 2 and 3,occur shear failure, not bending failure.

We want to get 7 datas about the shear-bearing capacity of this 7 beams, in the best case, we can see that there is one or two method which fits for deep beams between reinforcement of elevation and horizontal.

Theoretic analysis and simulation analysis. We will also try to estimate the shearing capacity 
of deep beams by finding right STM and simulating with ANSYS 10.0.

Difficult points. There are 3 difficult points mainly :BFRP's anchorage problem、 the precision of simulation analysis , the foundation of STM of reinforced beams, this is also the focus of our work next.

BFRP and resinous bond's anchorage force are always lacking, BFRP bars may spall crack from resinous bond, it is a waste of BFRP's strength. so we choose BFRP bar with sand-blasting to increase the frictional force, for the sake of assurance, we will try to set up mechanical anchorage at the end of BFRP bars ${ }^{[3}$ and 5$]$.

Resinous bond and BFRP、 concrete's contact is a coupled problem in ANSYS, how to control precision? First, we need to do a simple example, secondly, we should keep debugging.

Deep beam unreinforced's STM is simple relatively, but deep beam reinforced's STM is difficult, because we will translate BFRP bars's effect to STM's tie. It is difficult to control, we have to do it after experiment.

\section{Summary}

Our work are just begin recently, experiment was interrupted by errors of school's testing machine, theoretic analysis and simulation analysis are also just start, perhaps you will say my article has nothing significative, but we are doing now, interrelated results will publish within the year, more important in my opinion, idea is as important as action. Reinforcement for shearing of deep beam with BFRP bar is black, but we are doing.

\section{Acknowledgements}

Supported by Program for Liaoning Excellent Talents(LNET)and Liaoning Province Science Public Research Fund Project.

\section{References}

[1] Li Rong, Teng Jin-guang, A New Technique for strengthening concrete structures-near surface mounted FRP reinforcement, INDUSTRIAL CONSTRUCTION, 4(2004)5-10.

[2] Li Jun-feng, Liu Jing-yuan, Properties comparison of four FRP materials and the applications of them in reinforcement of civil engineering, SHANXI ARCHIT ECTURE, 4(2008)172-173.

[3] Huo Bao-rong, Zhang Xiang-dong, Experimental study of mechanical properties of the BFRP bar in different diameters, Journal of Shenyang Jianzhu University ( Natural Science), 4(2011) 626-630.

[4] Zhu Hong, Qian Yang, Mechanics Performance of FRP Tendons Used in Engineering Structure, Journal of Architecture and Civil Engineering,3(2006)26-31

[5] Zhou Chao-yang, Review of research on reinforced concrete beams shear-strengthened with FRP, Journal of Architecture and Civil Engineering, 2(2011)1-7.

[6] Code for design of concrete structures(GB50010-2010),China architecture and building press, Bei jing,2011.

[7] Wei Wei-wei, GONG Jin-xin, Strut-and-tie design method based on Chinese code, Journal of Building Structure (Supplementary Issue), (2008)287-293.

[8] Ye Lie-ping, Application of Strut-and-tie Model in Design of Reinforced Concrete Deep Beams, Journal of Architecture and Civil Engineering,2(2009)81-86. 